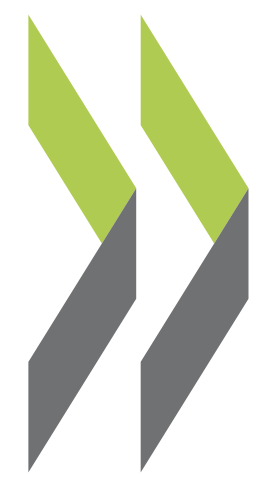

PEB Exchange, Programme on Educational Building 2001/10

\author{
School Building \\ Organisation in Greece
}

OECD

https://dx.doi.org/10.1787/786100402633 


\section{SCHOOL BUILDING ORGANISATION IN GREECE}

The national organisation responsible for school buildings in Greece has been converted into a public limited company. The School Building Organisation (SBO) was established in 1962 to design and construct new buildings and provide educational equipment. In 1998 the SBO was transformed into an S.A. (Société Anonyme) supervised by the Greek Minister of Education with the Greek state as the sole shareholder.

The SBO S.A. carries out construction projects and studies for both the public and private sectors. It works with the government agencies that construct school buildings (i.e. regional, prefectural governments and local authorities) and is responsible for:

- financing the national school building programmes;

- providing technical and scientific consultation to the decentralised services of the state;

- funding or co-funding construction projects;

- purchasing or expropriating building lots;

- providing technical studies (architectural, electrical and engineering) and supervising the construction of new schools upon request;

- equipping the country's schools;

- installing prefabricated classrooms to relieve crowding or create space for laboratories, libraries, cultural events, etc.

- attending to the development of the educational systems and pedagogical needs;

- designing and studying ways to adapt the educational infrastructure as needed.

The Organisation also builds schools for Greeks living abroad, the first being in Munich, Germany.

The transformation of the SBO into a limited company resulted firstly in a decrease in bureaucracy and secondly in a by-pass of the public accounting system. The change of status has had a positive effect on the learning environment in that problems related to school facilities are solved quicker.

Between 1996 and 1999 the amount of public finances invested in educational infrastructure more than tripled, from 22866 million drachmas to 74970 million. From 1997 through 2000, the SBO S.A. expropriated 290 building lots with a total area of 67 hectares and a total value of

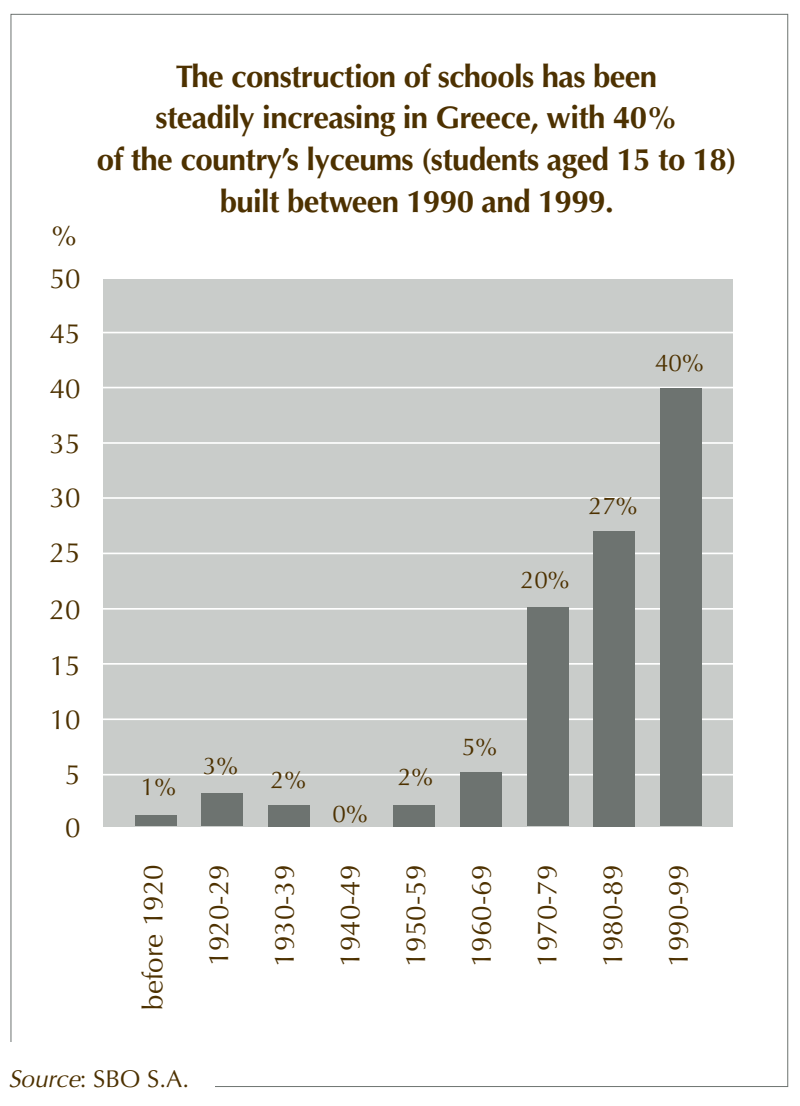

GRD 50 billion. It is currently carrying out 218 projects involving 2170 classrooms, with a budget of GRD 72 billion. In the year 2000, the SBO carried out a pilot project for 32 all-day primary schools. It is now undertaking a project for 200 new ones.

The SBO S.A. believes that infrastructure for culture and creativity, sports and laboratory learning are necessary elements in modern school buildings. By 2004 it plans to build 100 indoor gymnasiums throughout the country. New indoor and outdoor theatres, multi-use halls and arts education centres will be co-funded by local authorities. The Organisation is redesigning the national building

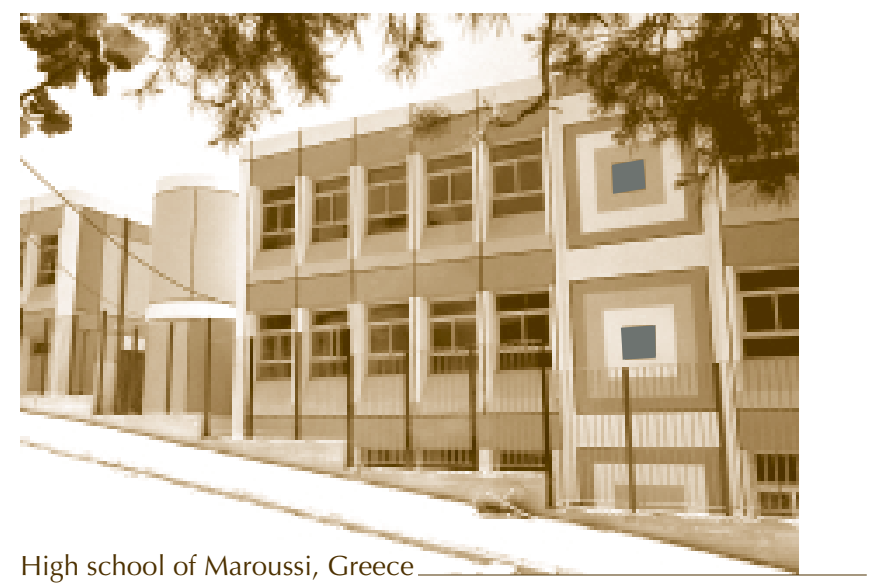




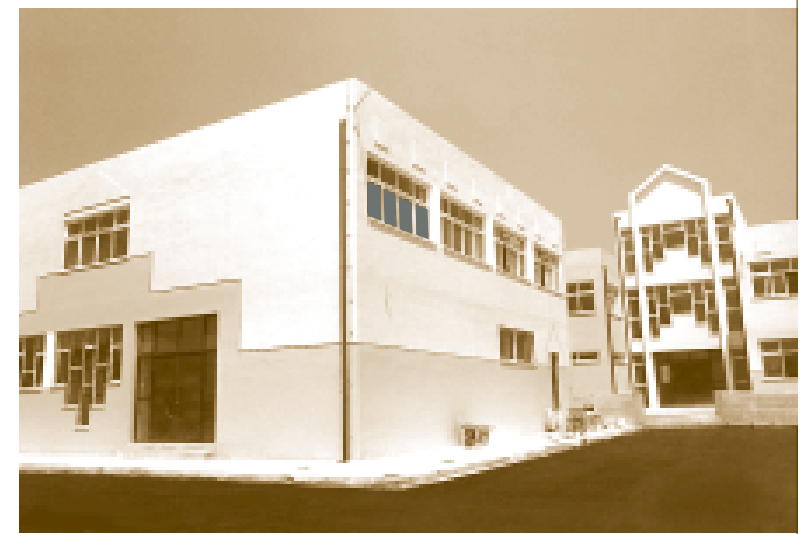

High school of Kalamata

programme for comprehensive lyceums and is constructing computer rooms, physics and chemistry laboratories, technology workshops and school libraries which allow for easy supervision and facilitate the educational process for teachers and students.

The new building programme is in line with a concern expressed by the Minister of National Education and Religious Affairs, Petros Efthymiou: "Absolutely essential for the full effective operation of schools is the securing of upgraded materials and technical infrastructure, laboratories, equipment and pedagogical material, contributing to schools' better internal functioning. ... Our objective is for instructors to offer students knowledge, care and attention in modern, attractive, people-oriented classrooms."

In an effort to make schools more attractive and inspiring, and looking less like prisons, the Organisation is doing away with asphalt and making schoolyards out of natural materials (earth, stone and wood). It is building open-air theatres, arbours, wooden seating and playgrounds. In Attica, the SBO S.A. is creating parks for 20 primary schools and planting greenery around 80 schools and aims to generalise this programme.

The SBO S.A. underwent three years of restructuring: it modernised its administration and operations, developed research programmes and increased incomes and social benefits for its employees. The Organisation created new regulations which simplified procedures and shortened decision-making time. Operational management was changed to speed up financial decision-making.

At the initial stage of privatisation, the main problem encountered was the opposition of the employees to the new situation, due mainly to a feeling of insecurity; they

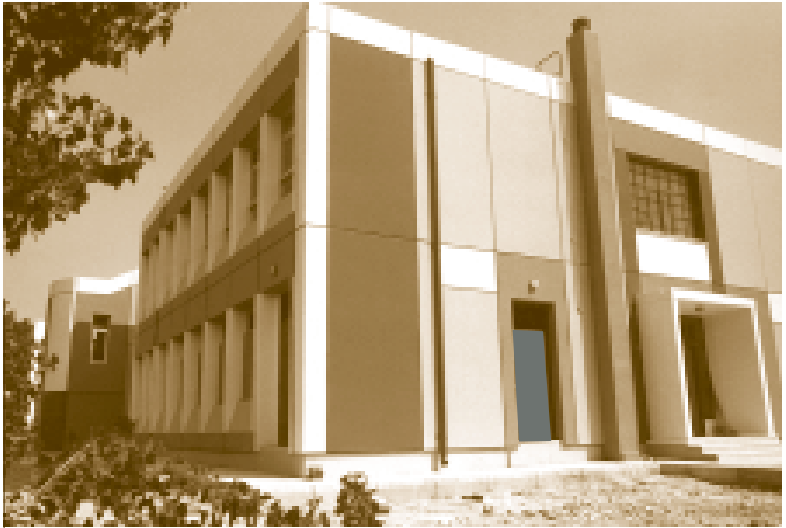

Primary school of Rafina

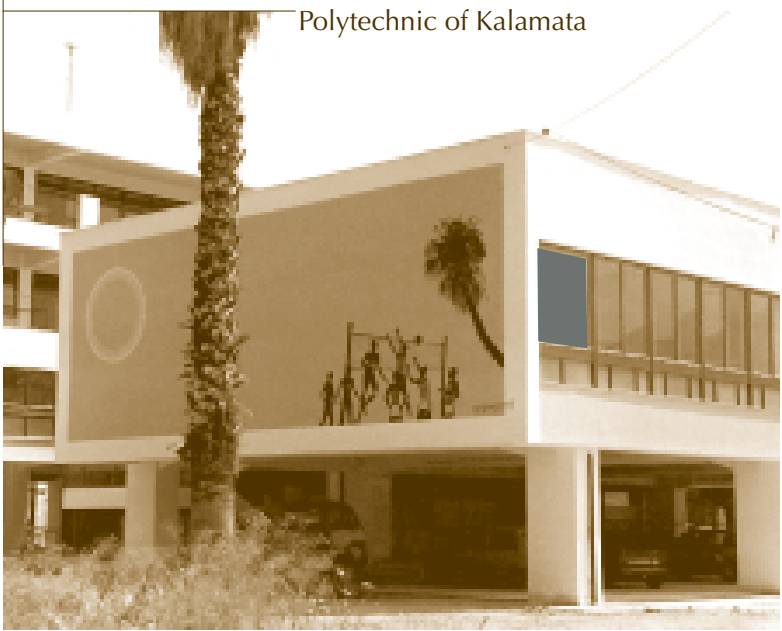

feared losing their jobs and their permanent status. Relevant legislation was passed that secured their positions and thus restored their confidence.

The SBO is credited by the national budget for all expenditures related to infrastructure throughout the country. The transformation of the SBO brought about an important increase in productivity; as a result, the Organisation has absorbed more money from the national budget and the $2 \mathrm{~d}$ CSF, a set of integrated development projects co-financed by the European Union and the Greek state.

For more information, contact:

School Building Organisation S.A.

30 Favierou Street

Athens 10438

Greece

Fax: 3015249676 